\title{
Kwashiorkpr: more hypothesis testing is needed to understand the aetiology of oedema
}

\section{Mark J. Manary ${ }^{1}$, Geert Tom Heikens ${ }^{2}$ Michael Golden'. \\ 1Department of Pediatrics, Washington University School of Medicine 2Department of Paediatrics \& Child Health, College of Medicine, \\ University of Malawi \\ 3Department of Medicine and Therapeutics, University of Aberdeen, Scotland.}

Kwashiorkor is severe childhood malnutrition characterised by oedema, often showing as swelling in the hands and feet. (1) In the last 20 years the WHO nomenclature has referred to kwashiorkor as oedematous malnutrition.

\section{Epidemiology}

Kwashiorkor is almost never seen in the developed world. Widespread in sub-Saharan Africa and common in Southeast Asia and Central America, kwashiorkor occurs in young children living in areas with endemic food insecurity or famine; prevalence varies by geographic area, with reported levels ranging up to $6 \%$ in some chronic foodinsecure communities and occasionally to one quarter of young children in areas facing famine. (2) Children from rural communities, particularly those from non-pastoral subsistence farming areas without cattle, are more likely to present with kwashiorkor than other children. The typical age of presentation is 1-3 years, kwashiorkor affects both girls and boys equally, and remains a major problem in food insecure regions of the world.

\section{Previous hypotheses concerning the aetiology}

The aetiology of kwashioror is truly not known. Most frequently, diets that are based on maize, cassava or rice are associated with kwashiorkor. (3) Kwashiorkor is not the result of prolonged breastfeeding, and neither deficiency in protein intake nor low levels of antioxidants in the diet are considered primary causal factors of kwashiorkor as the diet of children with marasmus have similar deficiencies. (4) Higher levels of aflatoxins have been found in the serum and liver of children with kwashiorkor than in marasmus. (5) Hypotheses have been advanced over the last 100 years suggesting that protein deficiency, hypoalbuminemia, and excessive oxidant stress cause kwashiorkor. Evidence associating these aetiologies with kwashiorkor have been cited, however dietary supplements of protein and antioxidants in children who are high risk for kwashiorkor have not been shown to reduce the risk of kwashiorkor (6), and oedema resolves on a restricted protein diet. (7) Aflatoxin intoxication has been advanced as an aetiology of kwashiokor, but kwashiorkor is seen in populations without evidence of ingestion of aflatoxin and this is not supported by studies of post-mortem tissues (8). Other social and economic risk factors include recent cessation of breastfeeding, recent infection, high birth order, incomplete immunization, and disruptions in the child's caretaker's status such as parental death, not living with a parent, unmarried caretaker, young age of mother, living in a temporary home, or parents not owning land. Recent measles infection has been found as a risk factor for the development of kwashiorkor, many caretakers report diarrhea as a precipitating factor in kwashiorkor.

\section{Pathophysiology}

Kwashiorkor affects most major organs systems. There is a profound reduction in whole body potassium to about $35 \mathrm{mmol} / \mathrm{kg}$ (normal is $44 \mathrm{mmol} / \mathrm{kg}$ ), magnesium and phosphorus. (9) This corresponds to loss of intracellular ions. Profound, life-threatening hypokalaemia and hypophospataemia are observed in severe cases. Though hyponatraemia occurs, total body sodium is elevated. Cardiac output is diminished on average by $30 \%$ in kwashiorkor, and renal fractional sodium excretion reduced by up to $70 \%$. Moderate anaemia (haemaglobin $80-100 \mathrm{~g} / \mathrm{L}$ ) is seen in most cases, but plasma free iron is raised. Fat accumulates in the intracellular space of the liver, which is the result of a decreased ability to transport and metabolically process fat. The villi of the small bowel are in general atrophied. The brain shows atrophy in the white matter. Without understanding the aetiology, a coherent understanding of pathophysiology is difficult. The unifying pathophysiologic concept of kwashiorkor is that cell membranes are damaged throughout the body. This damage results in an egress of potassium and water from cells of all types, and dysfunction in all organ systems.

\section{A potential mechanism of oedema}

A potential mechanism by which peripheral oedema occurs in kwashiorkor may well be related to release of water that is normally bound to glycosaminoglycans. Glycosaminoglycans are long polysaccharides consisting of a repeating sulphated carbohydrate units, bound to short protein core in all connective tissues and basement membranes of the body. Glycosaminoglycans contain moieties that are subject to oxidation/ reduction, and they bind water avidly through cohesive forces of "structured water" similar to that found in a gel. . Recent studies show that children in kwashiorkor have abnormal renal architecture that can be explained by loss of glycoseaminoglycans (10) and they lose glycosaminoglycans from the intestine (11) (particularly heparan sulfate proteoglycan); the loss of the ability of glycosaminoglycans to retain water in the form of a gel, may cause the appearance of pitting oedema.

\section{Novel hypotheses regarding etiology}

Apart from mechanisms that disrupt glycosaminoglycans or alter the redox (oxidation/reduction) state of the cells, there are other putative etiologies that require examination.

First, the development of kwashiorkor occurs only when the diet provides marginal amounts of macro- and micronutrients, but inadequate dietary intake of those essential nutrients so far examined is not a sufficient to damage cell membranes resulting in generalized oedema. Another interacting, coincident environmental factor must play an important role in the pathogenesis of kwashiorkor. The gut flora constitute a relatively uncontrolled metabolic system capable of synthesizing noxious and beneficial compounds and altering the dietary constituents. Populations of gut flora change with change with diet and physiological state. (12) The gut microbiota can work synergistically or antagonistically with the human host as they metabolically consume and process nutrients. (13) The gut microbiota have been shown to render some dietary toxins innoxious (14), but also to produce toxic metabolites capable of damaging the brain, 
liver or kidney. (15) The 1014 bacteria present in the human intestine produce metabolites which may exert a potent effect on the human host. Perhaps kwashiorkor is the result of changes in the gut microbiota that favor the production of metabolites that insult the human cell membrane integrity in an undernourished host, or disruption of the gut microbiota's protective function with respect to environmental toxins.

A second hypothesis is that a change in vanadium metabolism, either through a dietary deficiency or an alteration in the chemical form of the metal, may cause the sodium retention characteristic of kwashiorkor. $(16,17)$ Vanadate is a very potent inhibitor of the sodium pump at physiological concentrations. The sodium pump is responsible not only for transport across cell membranes but also for the reabsorption of sodium from the kidney. Failure to inhibit the reabsorption of sodium either because of a vanadium deficiency or conversion of vanadate to the inactive vanadyl ion could lead to salt and water retention and thus to edema formation. The serum levels of vanadium are low in kwashiorkor. (18)

Third, although kwashiorkor has not been prevented with an antioxidant cocktail (6), there is consistent evidence of oxidative stress in these children, with low levels of antioxidants, and elevated levels of pro-oxidants in the blood. Survival is improved if sulphur containing antioxidants are given during treatment. (19) The metabolites of these nutrients particularly, selenium and sulfur, are responsible for maintaining the redox level in the cells. The intracellular environment is much more oxidized than normal (20) which would account for the pathological features of kwashiorkor (membrane damage, fatty liver, skin lesions) and may be one mechanism whereby glycosaminoglycans are lost, the valences of vanadium are changed and the metabolites coming from small bowel bacteria exert their toxic effects.

However, without determining the precise etiology and pathogenesis of kwashiorkor we are not in a position to formulate rational or effective prevention strategies. This is important, because, unlike marasmus, there is no "moderate" or "mild" kwashiorkor whereby we can recognize the condition in its early stages and prevent deterioration to a stage when the condition is often lethal.

\section{References}

1. Waterlow JC. Protein Energy Malnutrition. Edward Arnold 1992.

2. Scrimshaw NS, Behar M, Viteri F et al. Epidemiology and prevention of severe malnutrition (kwashiorkor) in Central America. Am J Public Health 1957;47:54-62.

3. Williams CD. Kwashiorkor: a nutritional disease of children associated with a maize diet. Lancet 1935;229:1151-2.

4. Lin CA, Boslaugh S, Ciliberto HM et al. A prospective assessment of food and nutrient intake in a population of Malawian children at risk for kwashiorkor. J Pediatr Gastroenterol Nutr 2007;44(4):487-93.

5. Hendrickse RG, Coulter JB, Lamplugh SM et al. Aflatoxins and kwashiorkor. Epidemiology and clinical studies in Sudanese children and findings in autopsy liver samples from Nigeria and South Africa. Bulletin de la Societe de Pathologie Exotique et de Ses Filiales 1983;76(5):559-66.

6.Ciliberto H, Ciliberto M, Briend A et al. Antioxidant supplementation for the prevention of kwashiorkor in Malawian children: randomised, double blind, placebo controlled trial. BMJ 2005;330(7500):1095-6.
7.Golden MH. Protein deficiency, energy deficiency, and the odema of malnutrition. Lancet 1982;1(8284):1261-5

8. Golden MH. Oedematous malnutrition. Br Med Bull 1998;54:43344.

8. Golden MH. Oedematous malnutrition. Br Med Bull 1998;54:43344.

9. Golden MH. The effects of malnutrition on the metabolism of children. Trans Roy Soc Trop Med Hyg 1988;82:3-6

10.Golden MH, Brooks SE, Ramdath DD, Taylor E. Effacement of glomerular foot processes in kwashiorkor. lan 1990;336:1472-4.

11.Amadi B, Fagbeni AO, Kelly P, et al. Reduced production of sulfated glycosaminoglycans occurs in Zambian children with kwashiorkor but not marasmus. Am J Clin Nutr 2008;89:592-600.

12.Backhed F, Ding H, Wang T, et al. The gut microbiota as an environmental factor that regulates fat storage. Proceed Natl Acad Sci 2004;101:15718-23.

13.Karasov WH, Carey HV. Metabolic teamwork between gut microbes and hosts. Microbe 2009;4:323-8

14.Swann J, Wang Y, Abecia L, et al. Gut microbiome modulates the toxicity of hydrazine: a metabonomic study. Mol BioSyst 2009;5:351-5.

15.Michalke K, Schmidt A, Huber B, et al. Role of intestinal microbiota in transformation of bismuth and other metals and metalloids into volatile methyl and hydride derivatives in humans and mice. Appl Environ Micorbiol 2008;74:3069-75.

16.Anonymous. Nutritional oedema, albumin and vanadate. lan 1981;1:646-7.

17. Golden MH, Golden BE. Trace elements: potential importance in human nutrition with particular reference to zinc and vanadium. $\mathrm{Br}$ Med Bull 1981;37:31-6.

18.Burger FJ, Hogewind ZA. Changes in trace elements in kwashiorkor. S Afr Med J 1974;48:502-4.

19.Becker K, Pons-Kuhnemann J, Fechner A, Funk M, Gromer S, Gross HJ, Grunert A, Schirmer RH. Effects of antioxidants on glutathione levels and clinical recovery from the malnutrition syndrome kwashiorkor--a pilot study. Redox Rep 2005;10:215-26.

20.Golden MH, Ramdath DD, Golden BE. Free radicals and malnutrition. In: Dreosti IE, ed. Trace Elements, Micronutrients and Free Radicals. Totowa, New Jersey: Humana Press 1991:199-222. 